\title{
Implementation of Flipgrid as a Self-Reflection Tool for Student Engagement- A Pilot Study
}

Tyler M. Kiles, PharmD; Julia Vishenchuk, Pharmacy Student; Kenneth C. Hohmeier, PharmD

Department of Clinical Pharmacy and Translational Science, University of Tennessee Health Science Center College of Pharmacy

\section{ABSTRACT}

Background: Self-reflection is important for professional development, critical thinking, and engagement. However, self-reflection is not habitual or instinctive, and reflection assignments are often met with resistance from students. While written reflections are popular, other self-reflection mediums should be investigated.

Innovation: Flipgrid by Microsoft, an online video response tool, was used in an elective course for self-reflection and student engagement. To assess the impact of Flipgrid on the student experience in the course, two cohorts of students were evaluated. Overall $96 \%$ of respondents reported satisfaction with Flipgrid as an educational tool, however engagement was not significantly increased over the use of written reflection.

Implications: The results of this pilot study suggest that Flipgrid appears to have potential as a self-reflection tool, but may not be a "magic-bullet" to increase student engagement. Recommendations and considerations for implementing Flipgrid into a course to facilitate student engagement are provided.

Keywords: Flipgrid, reflection, engagement, online learning, remote teaching

\section{DESCRIPTION OF THE PROBLEM}

Self-reflection is important for professional development, critical thinking, and engagement. However, self-reflection is not habitual or instinctive for many, and reflection assignments are often met with resistance from students. ${ }^{1}$ Written assignments like a traditional self-reflection can seem like "busy work" to students. ${ }^{1}$ Reflection also requires independent critical thought, which demands mental energy, and today's students are often easily distracted. Additionally, students may not see a direct, tangible benefit of the mental effort that they are tasked with. However, sincere and honest reflection is essential for growth, thus, it is valuable to explore strategies that can increase the effectiveness of self-reflection for student pharmacists.

While written reflections are popular, other self-reflection mediums have been investigated in education such as: verbal storytelling ${ }^{2}$, photographic essays ${ }^{3}$ and Photovoice ${ }^{4}$. These audio and visual mechanisms have shown promise in eliciting meaningful self-reflection while engaging students in their learning. These mediums may be effective, but may also take considerable time and effort to design, implement, and assess. These platforms also do not integrate into existing learning management systems. It is also valuable to discover and share ways to engage students online in remote learning environments.

\section{Statement of the Innovation}

The University of Tennessee Health Science Center (UTHSC) College of Pharmacy has campuses in Memphis, Nashville, and

Corresponding author: Tyler M. Kiles, PharmD

Department of Clinical Pharmacy and Translational Science University of Tennessee Health Science Center

College of Pharmacy

Memphis, TN; Email: tkiles@uthsc.edu
Knoxville. The investigators were interested in ways to engage students in the classroom, including students on remote campuses across the state. It was hypothesized that Flipgrid may be utilized as: 1) a self-reflection tool and 2) a strategy to enhance student engagement. Flipgrid was piloted with a small group of students enrolled in a Community Pharmacy Elective Course in Spring 2020.

\section{THE INNOVATION}

Flipgrid is an online social learning platform, by Microsoft, that allows participants to record and share short videos. Teachers set up an account and create 'grids' that act as communities for students to work in. Once the grid is created, it can be embedded directly into the learning management system, or shared with a link or QR code. Only those with a password or a school email address may access grids, in order to protect student privacy. The educator can create 'topics' with prompts, and the students post their video responses to the 'topic,' as if it was a discussion board. Educators can set video response times from 15 seconds to 5 minutes. Of note, all video responses remain visible for members of the grid, and students (and faculty) can also reply to each other's videos. Closed captioning and audio-only options can be enabled for inclusion of students with disabilities or religious restrictions. Videos can be viewed and evaluated online, downloaded as video files, or downloaded as computer-transcribed text files. Faculty can provide feedback to student responses via video, but there is an option for private written comments and/or customization of a rubric as well.

Flipgrid is free and easy to use and functions like similar videobased social media platforms (i.e. Instagram, Snapchat). It has been used to increase engagement in primary and secondary education, as well as online undergraduate courses. ${ }^{5}$ The use of Flipgrid in doctoral education is limited, but has been described in online Masters-level nursing programs. ${ }^{6}$ While many levels of learners have utilized Flipgrid as an online discussion platform, 
literature on the use of Flipgrid as a self-reflection tool has not been published. However, reflecting on an in-class activity was described as one of the " 9 New Ways to use Flipgrid in the Classroom" by the George Lucas Educational Foundation. ${ }^{7}$

The community pharmacy elective course is a live 15 -week elective for second-year PharmD students taught by community pharmacy faculty and guest lecturers across all three campuses. The elective course includes many activelearning components. The course has also historically included weekly written reflections on lecture content. A new course director was introduced in 2020 and Flipgrid was piloted with six guided prompts spread equally throughout the semester in lieu of the weekly written reflections. While this cohort had several opportunities to practice written reflections previously in the curriculum, this was the first time they were exposed to Flipgrid. The instructor attended a one-hour training provided through the university's teaching and learning center to learn about the Flipgrid platform. The link to Flipgrid was embedded in Blackboard Learn (Blackboard Inc. Washington, DC) and video time limits set by the instructor ranged from 2-5 minutes.

Throughout the semester, students individually responded to Flipgrid prompts on their own time, reflecting on their experiences, and providing the course director with course feedback on new activities. Deadlines for Flipgrid submissions were outlined in the course syllabus. Flipgrid prompts are listed in Table 1, each with the objective to examine personal beliefs and values within the context of a learning experience. Rubrics were customized through the Flipgrid platform, and individual responses counted towards $10 \%$ of the final course grade as class participation points. Student replies to other students' posts were encouraged, but were not evaluated for a grade.

Table 1. Flipgrid Reflection Prompts

\begin{tabular}{ll}
\hline Introduction* & 1) Your name \\
2) Where you're from \\
3) What community pharmacy experience you have \\
4) What your career goals are \\
5) What you hope to learn from this class
\end{tabular}

Community Competency

Reflection

Bootcamp Reflection

Workflow \& Management Reflection

Being the Change + Course Feedback
1) What did you enjoy about this activity?

2) What did you not enjoy about this activity?

3) Why do community pharmacists need to be community competent?

4) How might you apply this concept to your community pharmacy practice?

5) What role do you think pharmacists play in a community?

1) What did you like about this activity?

2) What did you not like about this activity?

3) What did you learn from this activity?

4) What concepts from this activity might you apply to your community pharmacy practice?

5) What suggestions do you have for this activity next year?

1) What have you learned from this portion of the course that you can apply to your community practice?

2) What is the most concerning business aspect of community pharmacy for you?

3) What can you do to better prepare yourself to be a practicing community pharmacist?

4) What additional training/information would you like to see from the college?

5) What do you think the profession of community pharmacy needs to change?

1) How can you "BE the change" in community pharmacy?

2) Did you learn what you were hoping to learn from the course?

Please provide feedback to the instructors:

3) I liked 4) I wish 5) I wonder if...

*or 3) Stop 4) Start 5) Continue

*Students were required to respond to an assigned classmate's video. Assignments were intentional to match students on different campuses. Faculty also individually responded to each student's video.

To assess the impact of Flipgrid on the student experience in the course, two cohorts were evaluated -Spring 2019 (traditional written self-reflections) and Spring of 2020 (Flipgrid self-reflections). Student perceptions of engagement and value of self-reflection strategy were captured via two brief online post-then-pre surveys administered via Qualtrics (SAP, Provo, UT) from March to May 2020. Students who took the course in
Spring 2019 were incentivized with a gift card raffle, while the 2020 cohort was given class time to participate. Student engagement was assessed using a modified version of the National Survey for Student Engagement (NSSE), a validated tool widely used in undergraduate education. The NSSE was modified to a post-then-pre format and shortened to 18 selected questions, which were used with permission from 
The College Student Report, National Survey of Student Engagement, Copyright 2001-19 The Trustees of Indiana University. ${ }^{8}$ The NSSE questions included 5 items regarding course participation and connecting course material to real-life, 2 questions regarding student ratings of quality of interactions with students and faculty, and 6 questions about the perceived contributions of the course to knowledge and personal development. The self-reflection strategy survey was a brief 15item Likert-scale questionnaire developed and validated through expert review. In this survey, students were asked to rate their satisfaction with their respective reflection tools, selfperceptions of the tools' effects, as well as whether or not they found it valuable, applicable, and worth the time. Data was analyzed with student T-tests with a $p$-value of $<0.005$ deemed significant (via GraphPad Prism 7.05/e, GraphPad Software, San Diego, CA). IRB approval was obtained from the UTHSC review board.

\section{CRITICAL ANALYSIS}

Forty-two students completed the course in 2019, and thirtyone students were enrolled in the course in 2020. The survey was offered during the COVID-19 outbreak, and despite the incentives, only 15 students completed the 2019 engagement survey (35.7\%) and 13 students completed the self-reflection assessment survey (30.9\%). Of the 2020 cohort, 29 students
(93.4\%) completed the engagement survey and 27 (87\%) completed the self-reflection survey. The demographics of both groups were comparable (both 73\% aged 22-25) and students in both cohorts were predominately white (40 and $55 \%$ ) and female (72 and 93\%).

All students in the 2020 cohort completed the Flipgrid assignments over the course of the semester as scheduled. Overall, 26 out of 27 students (96\%) in the 2020 cohort reported satisfaction (agree/strongly agree) with Flipgrid as an educational tool in the course. On a scale from 1 to 5 (strongly disagree to strongly agree), students also reported a preference for Flipgrid over written reflections (as previously conducted in other courses) (Mean +/- SD: 4.33 +/-1.02) and feedback via Flipgrid to written feedback (as previously received in other courses) (Mean +/- SD: $3.48+/-0.92$ ).

Within each of the cohorts, student ratings of engagement on the modified NSSE increased before vs after taking the community pharmacy elective. When comparing cohorts, for most data points, student ratings of Flipgrid self-reflections (by the 2020 cohort) were higher on average than ratings of written self-reflections (by the 2019 cohort), however these mean differences failed to reach statistical significance (Table 2).

Table 2. Student Ratings of Engagement and Reflection for Cohort 2019 (Written Reflections) vs Cohort 2020 (Flipgrid Reflections)



There were no statistical differences found between student perceptions of whether written reflections (2019) or Flipgrid (2020) was applicable $(p=0.70)$, valuable $(p=0.90)$, or worth the time $(p=0.44)$. 
View counts for each video were also available in the instructor view, and students appeared to be consistently viewing other student's content on the site (average watch count:1.8); however, students did not submit video responses to other students throughout the semester unless explicitly instructed to do so (as in the introduction).

The students in this pilot study strongly preferred Flipgrid over written reflections $(4.33+/-1.02)$. As we know that students struggle with self-reflection as a concept, meeting them where they are - an online social platform with short clips - may allow for them to express themselves freely, rather than feeling pressured to write to a certain length or to change their vocabulary to come across as professional. Flipgrid allows students to be more conversational about their learning experiences, which may result in greater depth of reflection. At first glance, the implementation of an online video response tool (that conveniently interfaces with learning management software) appears like an exciting opportunity for educators to connect with this new age of tech-savvy students. The results of this pilot study suggest that Flipgrid appears to have potential as an alternative self-reflection tool used in combination with other pedagogical techniques to facilitate learning.

\section{KEY ISSUES}

In general, Flipgrid was an easy-to-use and intuitive educational tool for both educators and learners, which students prefer over traditional, written self-reflection. However, it also had distinct disadvantages, which must be considered by course directors considering its use.

1) Instructor Time Commitment: In this study, the course director watched, graded, and provided feedback for all posted video responses over the semester. Though each video response was short, the course instructor spent approximately two hours submitting introductory video responses to all students. It is unlikely that this would be feasible for a single instructor to implement regularly or for a large class. Teaching assistance may be needed and/or limiting the submissions' video time or number of assignments where Flipgrid is used. Despite this time commitment, the tool was invaluable for the instructor in creating a more intimate environment and for getting-to-know the students, particularly those on the distance campuses.

2) Facilitating Discussion: The addition of Flipgrid in this course was an 'add-on' to supplement in-class interaction. Students interacted with Flipgrid to fulfill the class requirements, but despite its "social" interface, were not automatically willing to use the platform to engage in discussion organically.

3) Student Comfort: Anecdotal reports from students at the beginning of the course were that Flipgrid reflections took a long time because they were nervous that the whole class could see their videos, and some often wrote a paragraph first or recorded their short clip multiple times to "get it right". However, by the end of the course, this resolved as students adjusted to more comfort with the platform and their classmates.

\section{NEXT STEPS}

The use of Flipgrid in the study course will continue into the next offering; however, the instructor will create smaller grids to facilitate student comfort in self-reflection and will also reduce the number of assignments.

Future research could explore the depth of reflection, which may be greater in a video reflection format than a written format. Flipgrid could also potentially be used as an individual 'video diary' of sorts. Programs could consider using Flipgrid for students, faculty, and/or residents to practice and grow in selfreflection skills. Immediate transcription and collation of data makes this an attractive platform to collect fragments of qualitative data as well. And, in circumstances where individuals are remote (e.g. students on APPE, distant campuses) it may allow educators to maintain a more human and personal connection with participants to share their educational journeys.

Acknowledgements: The authors would like to acknowledge Nikki House, PhD, Academic Technology Consultant.

Conflicts of Interest: None

Financial Support: None

\section{REFERENCES}

1. Bouldin AS. Reflection is not reflexive. Am J Pharm Educ. 2017;81(9): Article 6832. doi:10.5688/ajpe6832

2. Gilliam EH, Brunner JM, Bolan J, et al. Cultivating a culture of reflection among pharmacy atudents through storytelling. Am J Pharm Educ. 2020;84(4): Article 7633. doi:10.5688/ajpe7633

3. Barromi Perlman E. Using visual reflective diaries of photographs of school buildings as a tool for empowering students in teacher training. Int J Qual Methods. 2016;115 doi: 10.1177/1609406916653760

4. Skoy E, Werremeyer A. Comparing photovoice to traditional reflection to identify student learning on a medical mission trip. Am J Pharm Educ. 2020;84(4): Article 7599. doi:10.5688/ajpe7599

5. Bartlett, M. Using Flipgrid to increase students' connectedness in an online class. eLearn Magazine Special Issue: Instructional Technology in the Online Classroom. Published December 2018. Accessed October 112020. https://elearnmag.acm.org/archive.cfm?aid=3236703

5. Serembus JF, Murphy J. Creating an engaging learning environment through video discussions. Nurse Educ. 2020;45(2):68-70. doi:10.1097/NNE.0000000000000701

6. Nieves, K. 9 new ways to use Flipgrid in the classroom. Edutopia. Published January 27, 2020. Accessed October 11, 2020. https://www.edutopia.org/article/9-new-waysuse-Flipgrid-classroom

7. Kuh GD. The national survey of student engagement: conceptual and empirical foundations. New Dir Inst Res. 2009(141):5-20. doi: 10.1002/ir283 